\title{
Carotid Artery Stenting: Second Consensus Document of the ICCS/ISO-SPREAD Joint Committee
}

\author{
Gaetano Lanza $^{a}$ Carlo Setacci $^{b}$ Alberto Cremonesic Stefano Riccid \\ Domenico Inzitari $^{\mathrm{e}}$ Gianmarco de Donato $^{\mathrm{b}}$ Patrizio Castelli $^{\mathrm{i}}$ Carlo Pratesi $^{\mathrm{f}}$ \\ Flavio Peinetti ${ }^{j}$ Jessica Lanza ${ }^{i}$ Augusto Zaninellig Gian Franco Gensini ${ }^{\text {h }}$ \\ ${ }^{a}$ Department of Vascular Surgery, IRCCS MultiMedica Hospital, Castellanza, ${ }^{b}$ Vascular Endovascular Surgery \\ Unit, Department of Surgery, University of Siena, Siena, ' ${ }^{\circ}$ Department of Medical and Surgical Cardiology, Villa \\ Maria Cecilia Hospital, Cotignola, 'Department of Neurology, ASL 1 Citta' di Castello e Branca, Citta' di Castello, \\ e Departments of Neurology and ${ }^{\mathrm{f}}$ Vascular Surgery, Careggi Hospital, ${ }^{\mathrm{g} S} \mathrm{~S}$ chool of Medicine, ${ }^{\mathrm{h}}$ Department of \\ Critical Care, University of Florence, Florence, 'Department of Vascular Surgery, Insubria University, Varese, and \\ jDepartment of Vascular Surgery, Regional Hospital, Aosta, Italy
}

\section{Key Words}

Carotid stenosis · Stenting $\cdot$ Consensus statement

\section{Abstract}

Background: A major debate in cerebrovascular medicine today is over the choice of the best treatment to implement for stenosis of the carotid artery. Carotid artery stenting is a less invasive technique than endarterectomy for the treatment of carotid stenosis, and is becoming more widely performed, particularly on patients with carotid artery stenosis who present also with comorbidities. To address the aspects related to the use of carotid artery stenting, an Italian multidisciplinary task force comprising the most representative scientific societies concerned with carotid artery disease was set up to provide neurologists, radiologists, cardiologists, vascular surgeons, and all those involved in stroke prevention and treatment with an updated, evidence-based consensus document. Summary: The task force followed a structured methodology to assess the literature on carotid stenosis in order to provide a summary of the main issues related to carotid artery stenting, including the definition of the grade of symptomatic carotid artery stenosis, indications for intervening on the carotid artery stenosis, establishing whether to perform either a surgical or an endovascular procedure, the training, credentialization, and competency needed by physicians to perform carotid artery stenting, acceptable complication rates and risk certification for carotid artery stenting, management of stented patients, durability of carotid artery stenting, and future tasks. Here, we outline the main findings of this effort. Key Messages: As for any guideline or consensus statement, each point is valid as long as the evidence on which it is based remains up to date. In a fast-evolving field of medicine such as that of carotid artery stenosis management, and in particular carotid artery stenting, the stimulation of continuous and fruitful discussion among all professionals involved is mandatory. We hope that this document may provide a standardized basis for the application of carotid artery stenting as implemented today.

(c) 2014 S. Karger AG, Basel

ICCS = Italian Consensus on Carotid Stenting Group.

ISO-SPREAD = Italian Stroke Organization - Stroke Prevention and Educational Awareness Diffusion Italian Guidelines.

\section{KARGER}

E-Mail karger@karger.com

www.karger.com/ced
(C) 2014 S. Karger AG, Basel

1015-9770/14/0382-0077\$39.50/0
Gaetano Lanza, MD

Department of Vascular Surgery, IRCCS MultiMedica Hospital Via Piemonte 70 IT-21053 Castellanza (Italy)

E-Mail gaetano.lanza@multimedica.it 


\section{Introduction}

The problems associated with the treatment of atherosclerotic carotid stenosis (CS), and especially with carotid artery stenting (CAS), are a major matter of debate in the field of cardiocerebrovascular medicine today. To address this issue, Italian societies have appointed a special multidisciplinary task force composed of (a) delegates designated by representative societies involved in carotid treatment - namely the Italian Society of Interventional Cardiology (SICI/GISE), the Italian Society of Vascular and Endovascular Surgery (SICVE), and the Italian Society of Neurology (SIN) - forming the Italian Consensus on Carotid Stenting group (ICCS), and (b) several members of the Italian Stroke Organization - Stroke Prevention and Educational Awareness Diffusion (ISO-SPREAD) guidelines group - a multidisciplinary association representing 42 Italian scientific societies and patient organizations in the field of cardiocerebrovascular disease, which, during the last 11 years, has released seven editions of evidencebased guidelines for stroke prevention and treatment (available at http://www.iso-spread.it). The task force aims to provide neurologists, radiologists, cardiologists, vascular surgeons, and all those involved in the prevention and treatment of carotid disease with a simple and updated evidence-based consensus statement on CAS. The current document updates the first consensus statement of the ICCS-SPREAD group [1] and addresses the main issues related to methodology, definition of symptomatic and asymptomatic CS, and indications and procedures for CAS, including the use of devices for preventing procedure-related embolic complications. The general methodology used to draw the document included the evaluation and 'considered judgment' not only of strong and weak results from randomized clinical trials, but also the weight of evidence, the methodological quality of studies, and transferability to different settings. Special attention was paid to the credentials and competency needed by physicians to perform CAS, including training, acceptable complication rates, and certification. The working group considered it appropriate to offer this second document to the clinical/scientific community in order to provide them not only with knowledge shared by cardiocerebrovascular clinicians and other professionals, but also to stimulate fruitful discussion among all those involved in this rapidly evolving field. The positions expressed herein are tailored for healthcare structures and policies in Europe, and as such they may not necessarily be applicable or equally appropriate for other healthcare systems, such as that in the United States.

\section{Methods}

\section{Grading of Evidence}

The task force decided to adopt the same methodology used to draw the first document [1] but complemented with a doublegrading system to facilitate comparisons of the recommendations issued in the documents: the first grading system (table 1) - reported herein with boldface type - was that used by the ISO group [2], which integrates the principles of the Scottish Intercollegiate Guideline Network (SIGN) [3] with the statistical considerations suggested by the Centre for Evidence-Based Medicine (CEBM), and allows to clearly distinguish between recommended best practice based on consensus without evidence (good practice point, GPP) and limited external evidence (level D); [4] the second grading system (table 2), which can be used for comparative purposes, was based on that by Sackett [5], and is given herein in square brackets. Although no direct equivalence between gradings can be established, in general terms, grade $[\mathrm{A}]$ of the second grading system includes grades $A$, most of $B$, and a few of $C$ of the first system; grade $[B]$ of the second system includes some of grade $B$, most of $\mathrm{C}$, and a few of D of the first system; grade [C] of the second system includes some of grade $\mathrm{C}$, all of D, and all GPPs of the first system.

\section{Consensus Development Procedure}

All of the scientific associations were represented in the writing committee, which assembled the material of the first document and new material from the literature into a draft, verified the consistency of grading with the methodology, submitted drafts for formal approval by the associations, received and, where appropriate, incorporated documented dissent positions, compared the draft with the first document, organized and managed revisions submitted by independent guideline users, and wrote the second document. The consensus procedure followed the Rand technique, and was corrected to account for possible documented dissent positions, which are always possible in such a fast-evolving field [6].

\section{Definition of the Grade of Stenosis}

Throughout this document, the grade of stenosis is expressed according to the criteria set out by the North American Symptomatic Carotid Endarterectomy Trial (NASCET) for angiographic diagnosis [7], or to criteria equivalent to NASCET for diagnosis based on echo-doppler velocimetry (table 3) [8].

\section{Definition of Symptomatic Carotid Stenosis and Risk \\ Evaluation}

Clinical trials on carotid endarterectomy (CEA) have conventionally defined CS as 'symptomatic' when it is correlated with at least one clinical episode of ipsilateral ocular or cerebral ischemia in the previous six months $[7,9]$. Although it is not possible to be completely sure that a CS is the actual cause of an episode, careful neurological work-up can reasonably exclude other causes (i.e., cardiac embolism and lacunar ischemia not attributable to artery embolism) [10]. However, the six-month period was arbitrarily chosen in those clinical trials. An analysis of trials has shown that, even a few weeks after the event, the risk associated with a symptomatic carotid lesion is not substantially different from that associated with an asymptomatic one $[11,12]$. On this basis, the ISO-SPREAD group and the working group of this document thought it appropriate to reduce this period to three months. Thus, we defined CS as symptomatic when it was correlated with at least 
Table 1. Levels of evidence and grading of recommendations, SPREAD System

\begin{tabular}{llll}
\hline Levels of evidence & Grading of recommendations \\
\hline $1++$ & $\begin{array}{l}\text { High-quality meta-analyses without heterogeneity; } \\
\text { systematic reviews of RCTs each with small CIs; or } \\
\text { RCTs with very small CIs and/or very small } \alpha \text { and } \beta\end{array}$ & A & $\begin{array}{l}\text { At least 1 meta-analysis, systematic review, or RCT rated as } \\
1++ \text { and directly applicable to the target population; or }\end{array}$ \\
\hline $1+\quad \begin{array}{l}\text { Well-conducted meta-analyses without clinically } \\
\text { relevant heterogeneity; systematic reviews of RCTs; } \\
\text { or RCTs with small CIs and/or small } \alpha \text { and } \beta\end{array}$ & A & $\begin{array}{l}\text { Systematic review of RCTs or a body of evidence consisting } \\
\text { principally of studies rated as 1+, directly applicable to the target } \\
\text { population, and demonstrating overall consistency of results }\end{array}$ \\
\hline $\begin{array}{l}\text { Meta-analyses with clinically relevant heterogeneity, } \\
\text { systematic reviews of RCTs with large CI, or RCTs } \\
\text { with large CI and/or } \alpha \text { or } \beta\end{array}$ & B & $\begin{array}{l}\text { A body of evidence including studies rated as 2++, directly } \\
\text { applicable to the target population, and demonstrating overall } \\
\text { consistency of results; or extrapolated evidence from studies } \\
\text { rated as 1++ or 1+ }\end{array}$ \\
\hline
\end{tabular}

$\begin{array}{ll}2++ & \begin{array}{l}\text { High-quality systematic reviews of case-control or } \\ \text { cohort studies; high-quality case-control or cohort } \\ \text { studies with very small CIs and/or very small } \alpha \text { and } \beta\end{array}\end{array}$

$2+\quad$ Well-conducted case-control or cohort studies with $\quad$ C $\quad$ A body of evidence including studies rated as $2+$, directly small CIs and/or small $\alpha$ and $\beta$ applicable to the target population, and demonstrating overall consistency of results; or extrapolated evidence from studies rated as $2++$

\begin{tabular}{llll}
\hline $2-\quad \begin{array}{l}\text { Case-control or cohort studies with large CIs and/or } \\
\text { large } \alpha \text { or } \beta\end{array}$ & \\
\hline 3 & Nonanalytic studies (e.g., case reports and case series) & $\mathrm{D}$ & Evidence level 3 or 4; or \\
\hline 4 & Expert opinion & Extrapolated evidence from studies rated as 2+; or \\
\hline$-\quad \begin{array}{l}\text { Meta-analyses with clinically relevant heterogeneity; } \\
\text { systematic reviews of trials with large CIs; trials with } \\
\text { large confidence intervals and/or large } \alpha \text { and/or } \beta\end{array}$ & Evidence from trials classified as - regardless of the level \\
\hline & GPP & $\begin{array}{l}\text { Recommended best practice based on the clinical experience of } \\
\text { the guideline development group, without research evidence }\end{array}$
\end{tabular}

$\mathrm{CI}=$ Confidence interval; GPP = good practice point; RCT = randomized controlled trial; SPREAD = stroke prevention and educational awareness diffusion group [1-3].

Table 2. Levels of evidence and grading of recommendations - the AHCPR System

\begin{tabular}{|c|c|c|c|}
\hline I & Evidence from large, well-conducted RCTs & A & $\begin{array}{l}\text { Good evidence: evidence from well-conducted RCTs or cohort } \\
\text { studies (levels I-III) }\end{array}$ \\
\hline II & Evidence from small, well-conducted RCTs & & \\
\hline III & Evidence from well-conducted cohort studies & & \\
\hline IV & Evidence from well-conducted case-control studies & B & $\begin{array}{l}\text { Fair evidence: evidence from other types of studies (levels IV } \\
\text { and VI) }\end{array}$ \\
\hline VI & $\begin{array}{l}\text { Conflicting evidence, but tending to favor the } \\
\text { recommendation }\end{array}$ & & \\
\hline VII & Expert opinion & $\mathrm{C}$ & Expert opinion (level VII) \\
\hline
\end{tabular}


Table 3. Equivalence between the degree of carotid stenosis and echo-Doppler velocimetry

\begin{tabular}{clll}
\hline $\begin{array}{l}\text { Carotid artery } \\
\text { stenosis, \% }\end{array}$ & $\begin{array}{l}\text { PSV ICA, } \\
\mathrm{m} / \mathrm{s}\end{array}$ & $\begin{array}{l}\text { EDV ICA, } \\
\mathrm{m} / \mathrm{s}\end{array}$ & $\begin{array}{l}\text { PSV ICA/ } \\
\text { PSV CCA }\end{array}$ \\
\hline $0-29$ & $<1.1$ & $<0.4$ & $<3.2$ \\
$30-49$ & $1.1-1.3$ & $<0.4$ & $<3.2$ \\
$50-59$ & $>1.3-2.3$ & $<0.4$ & $<3.2$ \\
$60-69$ & $>1.3-2.3$ & $0.4-1.1$ & $3.2-4.0$ \\
$70-79$ & $>2.3$ & $>1.1-1.4$ & $>4.0$ \\
$80-99$ & $>2.3$ & $>1.4$ & $>4.0$ \\
100 & absent & absent & absent \\
\hline
\end{tabular}

Degree of carotid stenosis defined by angiography using NASCET criteria $[7,8]$. CCA = Common carotid artery; EDV = end diastolic velocity; ICA = internal carotid artery; NASCET = north American symptomatic carotid endarterectomy trial; PSV = peak systolic velocity.

one clinical episode of ipsilateral ocular or cerebral ischemia in the previous three months.

A concept that has evolved in recent years is that of the individual's risk of stroke. This has become substantially more relevant with the fast-increasing application of (mainly endovascular) carotid interventions for asymptomatic CS (i.e., those not compatible with the aforementioned definition of symptomatic CS). An equally important notion is the intrinsic safety of the procedure, as performed in any given center (discussed below). The same calculations used in the studies on CEA to assess the advantages and disadvantages of an intervention should also be applied to those on CAS; the same rigorous classification, attribution, and statistical techniques to produce the NNT (number of patients needed to treat to prevent one negative outcome) for the different conditions considered should also be used and they should be directly comparable with those for CEA [13]. Similarly, an assessment of surgical risk should be produced, resulting in a proper and directly comparable estimation of the associated risk and possibly, for determining models for subjects at higher medical and surgical risk [14], to guide the clinical decision based on an actual documented and weighted trade-off between benefits and risks for the patient at the specific center with the specific anticipated procedure.

\section{Legal Considerations and Declaration}

Clinical guidelines are aimed to provide physicians with an updated and weighted synthesis of the current best external evidence adapted to local conditions. Nevertheless, guidelines cannot offer proof of the mechanisms that improve medical care, and however well they may be linked to the evidence, they must be interpreted sensibly and applied with good judgment. Furthermore, recommendations are issued on the basis of population statistics and may not necessarily be applicable to individual cases. Therefore, because acceptable standards of clinical care derive from responsible customary practice rather than from guidelines, clinical guidelines cannot be used to mandate, authorize or exclude treatment options: the mere fact that a guideline exists does not itself establish that compliance with it is reasonable under all circumstances or that noncom- pliance is negligent [15]. On the other hand, complying with the recommendations of a guideline is, for the vast majority of cases, the most appropriate and effective option: modern evidence-linked clinical guidelines seek to make the strengths, weaknesses and relevance of research findings transparent to clinicians, and their appropriate interpretation and application in individual cases likely generates better clinical care - and a safer medicolegal strategy than either uncritical disregard or unthinking compliance [16].

\section{Establishing the Indication for Either Surgical or Endovascular Treatment}

\section{Recommendation 1: Grade GPP [C]}

Each structure having available teams capable of performing CEA and CAS (as recommended in this consensus document) should set standard operating procedures (SOPs) on the choice of procedure to be applied. Except when indications are clearly established for either procedure, the choice will be performed by a team including an expert on stroke and experts on all disciplines involved, coordinated by a team coordinator chosen according to the local SOPs. The decision should take into account the locally evaluated risks of periprocedural and postprocedural complications with either procedure, as well as the patient's preferences and the locally available facilities and resources. The local risk rate should be communicated to the patient or the patient's representative at the time of obtaining informed consent.

\section{Recommendation 2: Grade GPP [C]}

A structure having available teams capable of performing CEA or CAS exclusively should evaluate each individual potential patient according to the same procedures indicated for a structure capable of performing both procedures, with the assistance of those external experts as needed. It will then be decided whether to perform the locally available procedure or to refer the subject to a structure able to perform the alternative procedure as needed. Information on the alternative procedures available and their relative risks and benefits should be given in any case to the subject, at the time of seeking informed consent. Establishing the indication for CAS or CEA is a condition for which the principles of multidisciplinary integration find a paradigmatic application but also for which no direct literature support is available. Indeed, in all of the trials performed on CAS/CEA, the indication to intervention was based on the available procedures and protocol, rather than according to an evidence-based, preset standard procedure. Consequently, only rational considerations are available to issue a recommendation.
Lanza et al. 
It is nevertheless of major relevance that all participating clinicians exhibit in their respective field the proficiency and judgment that individual clinicians acquire through clinical experience and clinical practice.

The items to be considered in this event are as follows:

- The structure of the local team and the applicable SOPs;

- The objective condition of the patient, established through an intensive collaboration that shall include at least a neurologist or stroke physician expert in cerebrovascular diseases; an expert in vascular and cerebral imaging; an expert in vascular surgery; an expert in endovascular procedures; and an expert in overall patient management within the structure;

- The number of individuals in the team is relatively unimportant because each individual can have $>1$ field of expertise (e.g., the expert in endovascular procedures can easily be the expert in vascular surgery);

- The team should have a coordinator. The exact background of the individual is relatively unimportant, so long as this person is authoritative and is able to establish good interaction with colleagues and patients alike. It is the responsibility of the team coordinator to promote the preparation and continuous updating of the team's SOPs, to evaluate the extent of resource requisition (in collaboration with the management) within the specific structure, to establish procedures for investigating and understanding the patient's predicaments and preferences that may influence the final decision, and to obtain the patient's informed consent for the procedure, whichever it may be, in a form acceptable to the structure's ethics committee and incorporated into the SOPs.

- It is the collective responsibility of the team to keep track of the best external evidence available, to weigh the recommendations of the best external evidence against the structure's facilities, and to record the team's performance and estimate the local breakpoint of CAS-associated risks and CEA-associated risks for any given condition. These estimates should be considered when recommending either procedure in a specific case [12]. It is also the team's collective responsibility to take the reasoned decision not to apply the recommendations indicated in this document in a specific case. It is also suggested that the team maintains a log of each decision and of the main items leading to the actual choice, to prevent later disputes.

Once the basic teamwork approach to establish the indication for CAS or CEA is accepted, a structure having teams capable of performing exclusively either CEA or CAS should evaluate, with the help of external experts, each patient with the same procedure indicated for a structure capable of performing both techniques. The (in-house or external) treatment options should be chosen according to the best balance between the benefits for the patient and the risks that would emerge from multidisciplinary evaluation. Available information on the alternative procedures and their relative risks and benefits should be given in any case to the patient at the time of seeking informed consent.

The consensus panel is aware that no scientific data supports this model in an evidence-based medicine approach. For this reason, further studies of the feasibility and economy of this method of establishing the indication for surgical or endovascular treatment should be performed.

\section{Carotid Artery Stenting}

\section{Recommendation 3: Grade A [A]}

The evidence obtained to date has demonstrated only partially - and only in expert centers of excellence - the equivalence, or the non-inferiority, of CAS with respect to CEA. Therefore, the data do not support a change in clinical practice from CEA to CAS as the intervention of choice for surgical treatment of suitable carotid artery stenosis.

\section{Recommendation 4: Grade B [B]}

CAS is preferable to CEA in patients with severe cardiac and/or pulmonary comorbidity, and in those presenting with specific conditions, such as paralysis of the contralateral laryngeal nerve, stenosis extended to the cranial region or the clavicular region, restenosis, previous tracheostomy or surgical intervention/radiotherapy of the neck.

By convention, severe cardiac comorbidity comprises: (a) congestive heart failure and/or severe dysfunction of the left ventricle, (b) cardiac surgery conducted in the previous six weeks, (c) myocardial infarction in the previous four weeks, and (d) unstable angina (Canadian Society class III/IV).

\section{Recommendation 5: Grade D [C]}

CAS should be avoided when the presence of endoluminal thrombotic or thromboembolic material is suspected.

\section{Recommendation 6: Grade A [A]}

In elderly patients (i.e., those $\geq 70$ years of age) without a high risk for surgery and without important comorbidities, CEA is preferable to CAS in the surgical treatment of carotid stenosis, especially if it is symptomatic. 


\section{CAS versus CEA: Considerations}

An extensive analysis of the available documentation yielded the following considerations:

- The documentation comparing CAS and CEA is extremely varied in quality, end points, selection criteria, and techniques for evaluating outcome (which are often not adequately specified in terms of who determined the outcome and how the outcome was determined) [17-23];

- There is substantial clinically relevant heterogeneity among the different studies (e.g., incidence rates substantially variable across studies and in comparison with the reference studies);

- There are serious methodological objections to the selection criteria, randomization procedures, and outcome evaluation of the studies [24];

- There are substantial clinically relevant discrepancies on the conditions conventionally considered to pose a high risk for surgery but not for stenting: e.g., data from the Carotid Revascularization Endarterectomy Versus Stent Trial (CREST) suggest that elderly patients (from here on intended as those $\geq 70$ years of age) have high stroke rates with CAS [25];

- The main studies comparing CAS and CEA, at variance with those that evaluated only CEA, do not include a medically treated control group. Therefore, medical management should be considered an alternative option to stenting for high-risk surgical patients.

On the basis of the aforementioned considerations and the latest Cochrane Review, a systematic switch from CEA to CAS was 'not indicated' until new, high-quality, unbiased information becomes available [17]. According to that meta-analysis, the primary outcomes at 30 days were: (a) not in favor of CAS when any stroke was considered (OR: 1.81; 95\% CI: 1.40-2.34; $\mathrm{p}<0.00001$; $\mathrm{I}^{2}$ : $12 \%)$ or when stroke of any type and death were combined (OR: $1.72 ; 95 \%$ CI: $1.29-2.31 ; \mathrm{p}=0.0003 ; \mathrm{I}^{2}: 27 \%$ ); (b) not in favor of CAS when death, any stroke, and myocardial infarction were combined (OR: $1.44 ; 95 \%$ CI: $\left.1.15-1.80 ; \mathrm{p}=0.002 ; \mathrm{I}^{2}: 7 \%\right)$; (c) in favor of CAS for myocardial infarction (OR: 0.44; 95\% CI: 0.23-0.87; $\mathrm{p}=0.02$; $\mathrm{I}^{2}: 0 \%$ ), cranial nerve palsy (OR: 0.08 ; $95 \% \mathrm{CI}: 0.05-0.14$; $\left.\mathrm{p}<0.00001 ; \mathrm{I}^{2}: 0 \%\right)$, and access site hematomas (OR: 0.37; 95\% CI: $0.18-0.77 ; \mathrm{p}=0.008$; $\mathrm{I}^{2}: 27 \%$ ); and (d) indistinguishable for stroke during long-term follow-up (the rate of ipsilateral stroke after the periprocedural period did not differ between treatments: OR: 0.93; 95\% CI: $\left.0.60-1.45 ; \mathrm{p}=0.76 ; \mathrm{I}^{2}: 0 \%\right)$. Age significantly modified the effect of treatment on the primary safety outcome: rates of perioperative death or any stroke did not differ significantly in patients younger than 70 years old, but were significantly increased with endovascular treatment compared with surgery in the older age group. The OR for the primary safety outcome was 1.16 (95\% CI: 0.80 1.67 ) in patients $<70$ years old, and 2.20 (95\% CI: $1.47-$ 3.29 ) in patients $>70$ years old (interaction $p=0.02$ ). The authors concluded that endovascular treatment is associated with an increased risk of periprocedural stroke and death when compared with endarterectomy. However, this excess risk appears to be limited to older patients. The longer-term efficacy of endovascular treatment and the risk of restenosis are unclear and require further follow-up of existing trials, and more trials are needed to determine the optimal treatment for asymptomatic CS [17].

Additional information was obtained from randomized studies: ICSS (CAVATAS 2) [26, 27] and SPACE [28] for symptomatic stenosis; EVA3S [29] for severe symptomatic stenosis; and CREST [25] for both symptomatic and asymptomatic subjects.

In ICSS [26], the perioperative incidence of stroke, death, and myocardial infarction was $8.5 \%$ in the CAS group and $5.2 \%$ in the CEA group (OR: 1.69 ; 95\% CI: $1.16-2.45 ; \mathrm{p}=0.006$ ), with the risks of any type of stroke (OR: 1.92; 95\% CI: 1.27-2.89) and death (OR: 2.76 ; 95\% CI: 1.16-6.56) significantly greater in the CAS group. In the ICCS substudy [27], patients treated with CAS had higher numbers of periprocedural ischemic brain lesions, which were smaller and more likely to occur in cortical areas and subjacent white matter than those in CEA patients. These findings may reflect differences in the underlying mechanisms of cerebral ischemia.

In the SPACE trial [28], the 30-day incidence of ipsilateral stroke or death was $6.84 \%$ with CAS and $6.34 \%$ with CEA: the study was stopped because, according to the statistical analyses conducted, the non-inferiority of CAS with respect to CEA would not have been demonstrated by the enrolment of the 2,500 patients anticipated in the protocol.

In this case, EVA3S [29] was also prematurely interrupted because the 30-day incidence of disabling stroke or death was 3.4\% (95\% CI: 1.7-6.7\%) for CAS and 1.5\% (95\% CI: 0.5-4.2\%) for CEA with OR 2.2 (95\% CI: 0.77.2). However, the authors concluded that the study confirmed a net superiority of CEA and raised doubts about the high incidence of complications encountered after CAS with respect to data obtained, for example, in the SAPPHIRE study [23]. According to them, this was attributable to the learning curve of the staff at the participating centers, which ended up penalizing the result
Lanza et al. 
of the stenting procedure. Criticisms have been raised against these studies [30].

In the SVS Vascular Registry study [31], in which outcomes were not determined by independent neurologists, the rate for death/stroke/myocardial infarction at 30 days after CAS was $7.1 \%$ for the symptomatic group and $4.6 \%$ for the asymptomatic group ( $\mathrm{p}=0.04)$, while with CEA they were $3.7 \%$ for symptomatic CS and $1.9 \%$ for asymptomatic CS ( $\mathrm{p}=0.05)$; comparison of the procedures was statistically in favor of CEA (combined risk of death/ stroke/myocardial infarction: $6.42 \%$ for CAS; $2.62 \%$ for CEA; $\mathrm{p}<0.0001$ ).

More convincing data on CAS was obtained by CREST [25], in which the participating centers were selected on the basis of adequate performance for both procedures. The trial did not reveal a significant difference between CAS (with concomitant cerebral protection in $96 \%$ of cases) and CEA for the primary four-year endpoint of death, stroke and myocardial infarction combined $(7.2 \%$ and $6.8 \%$, respectively; OR: $1.11 ; 95 \%$ CI: $0.81-1.51 ; \mathrm{p}=0.51$ ). The four-year risk of stroke or death was $6.4 \%$ for CAS and $4.7 \%$ for CEA (OR: 1.50 ; $\mathrm{p}=0.03$ ): in the symptomatic group, risks were 8.0 and $6.4 \%$ respectively (OR: 1.37 ; $\mathrm{p}=0.14$ ), and in the asymptomatic group they were $4.5 \%$ and $2.7 \%$ respectively (OR: $1.86 ; \mathrm{p}=0.07$ ). Regarding the perioperative risks of CAS and CEA, death was 0.7 and $0.3 \%$, respectively $(\mathrm{p}=0.18)$, stroke was 4.1 and $2.3 \%$, respectively $(\mathrm{p}=0.01)$, and myocardial infarction was 1.1 and $2.3 \%$, respectively $(\mathrm{p}=0.03)$. The combined endpoint during the perioperative period was not found to be statistically significant between CAS and CEA (symptomatic CS: 6.7 vs. $5.4 \%$, OR: 1.26 ; asymptomatic CS: 3.5 vs. 3.6\%, OR: 1.02). Moreover, the incidence of ipsilateral stroke in the postoperative period was equally low for CAS $(2.0 \%)$ and CEA $(2.4 \%)(\mathrm{p}=0.85)$. However, there were more cases of major ipsilateral stroke with CAS, and significantly more cranial nerve lesions with CEA ( $p>$ $0.0001)$. The authors concluded that the risk of the primary outcome of stroke, myocardial infarction, and death combined was not significantly different for CAS and CEA; however, there was a greater perioperative risk of stroke with CAS, and of myocardial infarction with CEA. They also noted that the perioperative risk of death and stroke for CAS in symptomatic patients was better in CREST (6\%) than in SPACE (6.8\%) or in ICSS (7.4\%), and, similarly, the risk after CEA was better in CREST (3.2\%) than in SPACE (6.3\%) and almost the same in ICSS (3.4\%). Quality of life at one year in CREST was worse in patients with perioperative stroke than in those with perioperative myocardial infarction.
Although criticisms have been raised against CREST [32], CAS was re-evaluated by many authors after this trial [33].

In the CaRESS study [34], the risk of death or nonfatal stroke four years on from CAS conducted with distal protection was equivalent to that for CEA. There were no significant differences in stroke or mortality rates between the high-risk and the non-high-risk groups, and no differences in outcomes between symptomatic and asymptomatic groups. After four years, the CAS group had a two-fold higher restenosis rate than the CEA group. The risk of death/stroke or death/stroke/myocardial infarction appeared to be higher following CEA than CAS among patients $<80$ years of age, yet there was no statistically significant relationship in death, stroke, or myocardial infarction for octogenarians.

From the SAPPHIRE study [23], preprocedural factors were used to develop a model predicting stroke or death within 30 days [35]. The findings were consistent with observations on risk factors for adverse events associated with CAS [36-40]. In the future, prospective testing should be performed to ascertain whether these models improve patient outcomes. In these evaluations, it is appropriate to take into account the different characteristics of patients referred to CAS or CEA. For example, in a recent study, the characteristics of the patients referred to CAS or CEA were compared for 44 clinical and demographic variables [41].

Moreover, the experience of centers and their operators must be taken into account. In the Medicare observational study [42], operator experience and outcomes were evaluated for CAS: adjusted outcomes following the procedure were worse among very-low-volume operators and early during an operator's experience.

However, in a systematic review and meta-analysis [43] of 11 randomized controlled trials on CEA versus CAS, the periprocedural risk of mortality or stroke was lower for CEA than for CAS (OD: 0.67; 95\% CI: 0.47$0.95 ; \mathrm{p}=0.025)$, mainly because of a decreased risk of stroke (OD: 0.65 ; 95\% CI: 0.43-1.00; $\mathrm{p}=0.049$ ), whereas the risk of death (OR: 1.14 ; 95\% CI: $0.56-2.31 ; \mathrm{p}=0.727$ ) and the composite endpoint for mortality or disabling stroke (OR: 0.74; 95\% CI: 0.53-1.05; $\mathrm{p}=0.088$ ) did not differ significantly. The odds for periprocedural myocardial infarction (OR: $2.69 ; 95 \% \mathrm{CI}: 1.06-6.79 ; \mathrm{p}=0.036$ ) or cranial nerve injury (OR: 10.2; 95\% CI: 4.0-26.1; p < 0.001 ) were higher in the CEA group than in the CAS group. In the intermediate term, the two treatments did not differ significantly for stroke or death (HR: 0.90; 95\% CI: $0.74-1.1 ; \mathrm{p}=0.314)$. The conclusion was that CEA 
was found to be superior to CAS for short-term outcomes, but the difference was not significant for intermediate-term outcomes. This difference was mainly driven by non-disabling stroke. Significantly fewer cranial nerve injuries and myocardial infarctions occurred with CAS. Moreover, a recent systematic review and meta-analysis of randomized controlled trials of CEA versus CAS concluded that, compared with CEA, CAS significantly increased the risk of any stroke but decreased the risk of myocardial infarction [44]. However, outcome data for asymptomatic patients were sparse and imprecise, so the conclusions applied primarily to symptomatic patients.

Finally, we have to consider the considerable differences between authoritative guidelines regarding the management of symptomatic and asymptomatic CS patients, as reported in a study comparing five recent guidelines (ACC/AHA, SVS, ESC, Australasian, NICE) [45].

In conclusion, in the presence of controversial and contradictory external evidence, a multidisciplinary team should carefully evaluate any subject for whom CEA or CAS is being planned, taking into consideration the performance index of the surgical and interventional team in the specific risk class, the presence of multiple risk factors and the patient's preferences. It is suggested that validated individual risk models, which are available for CEA, be rapidly developed for CAS as well. Because it is likely that in any given center a number of CS patients will not have a definite indication for either surgery or endovascular treatment, these patients may, with their consent, be randomized to comparative investigations in progress.

\section{CAS: Acceptable Complication Rates and Risk Certification}

\section{Recommendation 7: Grade A [A]}

In symptomatic patients with $>50 \%$ carotid stenosis, CAS, like CEA, should be performed only if the upper limit of the $95 \%$ confidence interval for 30-day complications (i.e., any stroke or death) of the center over the last years is certified to be $<6 \%$.

In patients with symptomatic stenosis of between 50 and $70 \%$, the advantage of CAS, like that of CEA, with respect to best medical therapy is modest during the first few years of follow up, but could be more evident in successive years, especially in the elderly, in males, in nondiabetic patients, or in those with recent ischemia, nonocular (but cerebral) symptoms, or ulcerated plaques.
In patients with symptomatic $>50 \%$ carotid stenosis, CAS, like CEA, is indicated early on, that is, within the first two weeks of the minor ocular or cerebral ischemic event.

\section{Recommendation 8: A [A]}

In patients with asymptomatic $>60 \%$ carotid stenosis, CAS, like CEA, should be performed if the upper limit of the $95 \%$ confidence interval for 30-day complications (any stroke and death) of the center over the last years is certified to be particularly low and well under 3\%. It is indicated that the advantages gained by the best invasive therapy and by the best medical therapy be compared, and further studies aimed at identifying subgroups of patients who are at the greatest risk if they are not subjected to the procedure and that would gain the most benefit. Even if the gain is only modest (absolute risk reduction for stroke 1\%/year) with respect to current medical therapy and progressive only after the 3rd year from the procedure, it would be helpful.

\section{Recommendation 9: Grade B [B]}

CAS should be performed with adequate cerebral protection, unless contraindicated for the individual case. Neurological complications should be evaluated by a physician expert in cerebrovascular diseases.

\section{Background}

This consensus statement does not take a definite position on specific procedures and the devices to be used during stenting, also in view of the rapid evolution of the field. Cerebral protection and relevant devices, the type of stenting, and the ultrasonography/imaging profile of the stenosis and plaque are all issues deserving adequate discussion, although until now no positions, except those on cerebral protection, are sufficiently supported by the evidence. On this point, current evidence supports the notion that stenting procedures are less prone to periprocedural risks when adequate cerebral protection is applied with a device the interventionist is familiar with and is an expert trained well in its use[46-51]. However, this statement is supported essentially by case series, some of which are quite large but probably not bias free [52]. Additional information will probably be obtained by ongoing studies, although they are not randomized as to the application of cerebral protection devices or techniques [53].

Although CAS and CEA are performed to prevent future cerebrovascular events, most CS patients, including those classified as symptomatic, will never experience a
Lanza et al. 
stroke before dying of another cause: in fact, the threeyear stroke risk for a medically treated symptomatic 70$99 \%$ CS is about 20\% [14]. However, the procedures themselves can cause disabling stroke and death. Thus, the objective of setting certified limits to the risk of short-term cerebrovascular events is to balance the benefits and risks for the patient, who should not be exposed to a greater intervention-related risk than a stenosis-related one [54].

\section{Interventional Risks and Benefits}

The only sensible measure of interventional risk is the short-term (30-day) periprocedural incidence of cerebrovascular events. However, a longer observation period is advisable. Unfortunately, there is currently no way of distinguishing between procedure-induced events, spontaneous events, and unrelated, independent events. But even if an early event might be completely independent in origin, allocating it to the intervention increases the margin of safety for the patient. The benefit from CEA is minor for symptomatic patients with 50-69\% CS (NNT = $21)$ and major for those with 70-99\% SC $(\mathrm{NNT}=14)$ when excluding patients with carotid near-occlusion [11], for whom the benefit from CEA is marginal. The benefit from CEA is still greater in patients with a high risk score according to current models, such as the elderly, males, non-diabetics, patients with a recent ischemia, and those with non-ocular but cerebral symptoms or with ulcerated plaques $(\mathrm{NNT}=3)$, and little, if any, in patients with a low risk score $(\mathrm{NNT}=100)$ [14].

Importantly, age is not a limiting factor for surgical treatment. In fact, the incidence of symptomatic CS increases with age and, therefore, it is mainly the older patient that benefits from surgery [55]. The benefit from surgery has been correlated also to other factors, such as the delay-to-surgery from the first presenting event. In fact, Rothwell et al. [56] re-analyzed the ECST and NASCET data sets and found that the benefit from surgery is greater for patients randomized to CEA within two weeks from the initial ischemic event (NNTs for ipsilateral stroke prevention at five years: 5 for patients randomized within two weeks; 125 for patients randomized after $>12$ weeks).

The perioperative risk rate for symptomatic patients after conventional CEA has been established to be $<6 \%$ for any stroke and death, and $<3 \%$ for disabling strokes and death [57]. For asymptomatic CS, it is 3\% for any stroke and death $[58,59]$. Although this is a restrictive evaluation, in the absence of more widely evaluated definitions these figures remain the yardstick by which to estimate interventional risk.

CAS Recommendations
Recently, in prospective, multicenter, high-surgicalrisk registries [60], the combined 30-day death and stroke rate for CAS was 5.3\% (95\% CI: 3.6-7.4\%) for symptomatic patients and $2.9 \%$ (95\% CI: $2.4-3.4 \%$ ) for asymptomatic patients, independent of unfavorable (anatomical or physiological) risk factors; in patients $\geq 80$ years, the rates were $10.5 \%$ (95\% CI: 6.3-16.0\%) and 4.4\% (95\% CI: $3.3-$ $5.7 \%)$, respectively. In patients with unfavorable anatomical features for surgery, the 30-day death and stroke rate was $1.7 \%$ (95\% CI: $0.0-8.9 \%)$ for symptomatic patients and $2.7 \%$ (95\% CI: $1.3-4.9 \%$ ) for asymptomatic ones, independent of age. However, procedural safety has increased remarkably over the last years, as shown by a number of large case series $[49,61-63]$, so rather than a reliable central estimate, these figures should be considered the upper acceptable limit of risk. This should be reflected in the recommendation, which, for the time being, should be applicable to both CAS and CEA, as long as the two procedures remain comparable in outcome as discussed previously.

Asymptomatic CS necessitates additional considerations. In asymptomatic patients, the overall benefit from CEA (or CAS) over the best current medical treatment is still not conclusively established. The benefit from CEA is modest, with an absolute risk reduction for stroke of only $1 \% /$ year over current medical therapy and a progressive trend only from the 3rd year onward. Moreover, it was more evident in certain subgroups of patients, such as those $<75$ years of age [59]. A recent systematic revision of cohort studies conducted on asymptomatic patients with $>50 \%$ CS demonstrated a progress in medical therapy in terms of reduced risk of ipsilateral stroke and any type of stroke, so much so that the benefit is equivalent to that of surgery [64]. The authors concluded that best medical therapy represents the best prevention strategy, at least until it is possible to identify the highest-risk patients who gain the most from surgery.

Thus, this consensus group recommends that a multidisciplinary team also formally considers the option of not intervening on these patients, prescribing instead the best current medical treatment while taking into account the patient's preferences as well as the individual diseaseassociated and procedure-associated risks.

A number of scoring systems have been recently proposed to predict the perioperative risk of stroke in CASoperated patients. An example is the Siena CAS scoring system, which considers the presence of predictive risk factors, which include cardiac disease, symptomatic CS, diabetes, lesion calcification and ulceration, native and 
ostial lesions, lesion length $>15 \mathrm{~mm}$, type III or bovine aortic arch and arch calcification, the need for pre-dilatation, a procedure time $>30 \mathrm{~min}$, and an operator's experience of $<50$ procedures [65]. The Siena CAS score predicts the perioperative risk of CAS within three categories: low risk or CAS I $(<1 \%)$, medium risk or CAS II (1-3\%), and high risk or CAS III (>3\%) (sensitivity: 0.82; specificity: 0.79). But the conclusion of the authors is that this scoring system needs to be validated in independent cohorts at different centers, preferably in a randomized comparison with CEA, before it can be recommended for application.

In the ACCF/SCAI/SVMB/SIR/ASITN consensus document [66], contraindications to CAS were the following: inability to achieve safe vascular access, severe tortuosity of the aortic arch and/or carotid artery, intracranial aneurysm requiring treatment, heavy lesion calcification, visible thrombus at the lesion, total occlusion, and long subtotal occlusion of the carotid artery (string sign). Moreover, the document highlighted that (a) there was insufficient evidence to support CAS for high-risk patients with asymptomatic $<80 \%$ CS or in any patient without high-risk features; (b) the results of ongoing randomized trials will define the future role of CAS in lowrisk patients; (c) further study is needed on asymptomatic high-risk patients to determine the relative merits of CAS compared with best medical therapy; (d) reimbursement is limited to qualified institutions and physicians when using FDA-approved stents and embolic protection devices on high-risk patients with symptomatic $>70 \%$ CS or on high-risk patients (i.e., those with symptomatic $>50 \%$ CS or asymptomatic $>80 \%$ CS) enrolled in a postapproval study.

\section{Risk Certification}

For public transparency and correctness toward patients, the surgical/interventional risks should be properly certified by external auditing. To this end, each group should indicate in advance the external auditor. It would be advisable that a neurologist with experience in cerebrovascular diseases and, in particular, in post-interventional neurological problems, be involved. Where such professional expertise is not available, a physician with experience in cerebrovascular diseases can be appointed, as long as he/she is not a member of the interventional group and does not have any common commitment with the group. The neurologist (or physician expert in stroke) must see every single patient before the procedure, on the day after the procedure, and 1 month afterward. If a neurological deficit is still present at 30 days, then a formal assessment of the residual disability at six months is also required. Data should be stored in a database and analyzed yearly with appropriate standardized statistical descriptions and analysis by independent personnel. The risk rate, as derived from these yearly analyses, should be incorporated into the information to be given to the patient before obtaining informed consent for the procedure, as previously indicated. When different teams are present at a center, each should be certified independently as to the risk of events. Data should be publicly available.

\section{CAS: Training and Expertise}

\section{Recommendation 10: Grade GPP [C]}

Once the basic skill for catheter-based intervention has been achieved by the already-active interventionist, the minimum recommended training to achieve competence is as follows:

(1) at least 150 procedures of supra-aortic vessel engagement (during diagnostic as well as interventional procedures) within 2 years, of which at least 100 as the primary operator;

(2) at least 75 carotid stenting procedures, of which at least 50 as the primary operator, within a 2 -year fellowship.

\section{Recommendation 11: Grade GPP [C]}

The minimum requirement to maintain technical skill (competence) is 50 carotid stenting procedures performed and documented by each primary operator per year.

\section{Background}

There is insufficient firm external evidence supporting the concept that training and competency are an essential background for any medical activity. This is a self-evident statement and constitutes the personal physician's contribution to evidence-based clinical decisions. Nevertheless, there is some indirect supporting evidence that theoretical training significantly facilitates appropriate clinical decisions, including training by computer simulation in the carotid stenting area $[67,68]$. In the specific field of CAS, relatively small series of cases have shown that the 'learning curve' flattens after about 80 interventions with regard to procedural risk, and after about 160 interventions with regard to procedural time (an item not so irrelevant, because it is related to patient discomfort and resource requisition) [69].
Lanza et al. 
Once established that competence and training are key factors that may affect patient safety, multispecialty consensus statements have supported a series of recommendations that, however, have been tailored for the United States [70-72]. These statements can be a valuable reference, but the ICCS/ISO-SPREAD panel has expressed the need that these training recommendations be adapted to the Italian and European setting, taking into account differences in the steps to specialization and in credentialing procedures.

\section{Competence}

All medical schools have their own curricula for acquiring the minimum necessary competence. It is not the aim of this consensus panel to intervene in these curricula. Nevertheless, the ICCS/ISO-SPREAD panel considers it mandatory to define an updated, minimum requirement for credentialing an interventionist as a primary CAS operator independently from the competence required by each medical school. In this perspective, the interventionist should be knowledgeable about all of the complex diagnostic and therapeutic process related to carotid pathology, from the basic cognitive skills for vascular medicine physicians (table 4 ) to the specific advanced cognitive and technical requirements for performing CAS (tables 5 and 6).

One of the main topics that remains poorly defined is the procedure recommended for maintaining competence. Participation in continuing medical education events and programs may be appropriate, as long as scientific societies actively participate in determining and assuring quality standards and program content. E-learning can also be appropriate, as long as it guarantees the participation of active trainees and the correctness and security of the verification procedures.

Within the sphere of competence, a special area is the technical skill required. Because all of the procedures are strongly operator dependent, minimum technical skill should be validated by independent, periodic certification, either by the individual colleges or by an interdisciplinary body.

\section{Training}

Training can be divided into 3 segments:

- Standard medical and specialty training, which is standardized by country, and often within the specific country by the individual school of medicine;

- Specific training for the procedure: interventional laboratory training (including preceptorship, proctorship, and computer-aided training);

- Specific training with individual devices.
Table 4. Carotid artery stenting - basic cognitive skills

Physiopathology of vascular diseases, atherosclerosis, and thrombosis

Systemic manifestations of atherosclerosis

Cardiovascular risk factors and their prevention and management

Physiopathology, clinical manifestations, natural history, evaluation, and management of cerebrovascular disease (TIA/ stroke), peripheral arterial disease, renal artery stenosis, extracranial cerebrovascular disease, aortic and peripheral artery aneurysms, and other arterial diseases

Physiopathology, clinical manifestations, evaluation, and management of venous thromboembolism

Prothrombotic disorders, including inherited and acquired hypercoagulable states

Physiopathology, clinical manifestations, evaluation, and treatment of chronic venous insufficiency and lymphedema

Preoperative evaluation and perioperative care of the vascular surgery patient

Noninvasive vascular tests, including duplex ultrasonography of peripheral arteries and veins, carotid arteries, renal arteries, and physiological tests of the peripheral circulation

Magnetic resonance and computed tomographic angiography

Conventional contrast angiography

Diagnostic criteria and technical limitations for each test

Once the standard skill for catheter-based intervention has been achieved by the already-active interventionist, the ICCS/ISO-SPREAD panel recommends the following specific training as a minimum to achieve the basic competence and technical skill required for a primary operator:

(1) At least 150 (diagnostic and interventional) procedures of supra-aortic vessel engagement, of which at least 100 as the primary operator;

(2) At least 75 carotid stenting procedures, of which at least 50 as the primary operator, within a 2-year fellowship.

These numbers are different to those of the learning curves reported in the literature [69-73] and also to the numbers given in specific articles on training, competence, and credentialing standards [72]. Nevertheless, the position of this consensus panel is based on the assumption that CAS must be performed only by high-level, welltrained interventionists. Being aware that baseline technical backgrounds are different for the various specialists, this consensus panel states that these are general recom- 
Table 5. Carotid artery stenting - advanced cognitive skills regarding physiopathology, assessment, and treatment of carotid artery disease and stroke

\begin{tabular}{|c|c|}
\hline Causes of stroke & $\begin{array}{l}\text { Embolization (cardiac, carotid, aortic, other) } \\
\text { Vasculitis } \\
\text { Arteriovenous malformation } \\
\text { Intracranial bleeding (subdural, epidural) } \\
\text { Space-occupying lesion }\end{array}$ \\
\hline Causes of stenotic carotid artery lesions & $\begin{array}{l}\text { Atherosclerosis } \\
\text { Fibromuscular dysplasia } \\
\text { Spontaneous dissection } \\
\text { Other }\end{array}$ \\
\hline Clinical manifestations of stroke & $\begin{array}{l}\text { Knowledge of stroke syndromes (classic and atypical) } \\
\text { Distinction between anterior and posterior circulation events }\end{array}$ \\
\hline Natural history of carotid artery disease & \\
\hline $\begin{array}{l}\text { Associated pathology (e.g., coronary and } \\
\text { peripheral artery disease) }\end{array}$ & \\
\hline $\begin{array}{l}\text { Diagnosis of stroke and carotid artery } \\
\text { disease }\end{array}$ & $\begin{array}{l}\text { History and physical examination: neurological and non-neurological (cardiac, other) } \\
\text { Noninvasive imaging: duplex ultrasound, magnetic resonance angiography, computed } \\
\text { tomographic angiography } \\
\text { Angiographic anatomy (arch, extracranial, intracranial, basic collateral circulation, } \\
\text { common anatomic variants, and non-atherosclerotic pathological processes) }\end{array}$ \\
\hline $\begin{array}{l}\text { Knowledge of alternative treatment } \\
\text { options for carotid stenosis and their } \\
\text { results (immediate success, risks, and } \\
\text { long-term outcome) }\end{array}$ & $\begin{array}{l}\text { Pharmacotherapy (antiplatelet agents, anticoagulation, lipid-lowering agents, etc.) } \\
\text { CEA: results from major trials (NASCET, ACAS, ECST, ACST), and results in patients } \\
\text { with increased surgical risk } \\
\text { Stent revascularization } \\
\text { Results with and without distal embolic protection }\end{array}$ \\
\hline Case selection & $\begin{array}{l}\text { Indications and contraindications for revascularization to prevent stroke } \\
\text { High-risk criteria for CEA } \\
\text { High-risk criteria for percutaneous intervention }\end{array}$ \\
\hline
\end{tabular}

Role of postprocedural follow-up and

surveillance

mendations and, consequently, that scientific societies may propose specific individual training programs oriented to focus their teaching activities on improving the real needs of each specialty.

In the CAPTURE 2 multicenter study [74], the most important determinants of perioperative CAS outcomes were site and operator CAS volume. A threshold of 72 cases was found to be necessary for consistently achieving a death/stroke rate below $3 \%$ in this later-phase singlearm study; background and non-study operator experience will affect this determination.

For the ICCS/ISO-SPREAD panel, the minimum requirement for maintaining technical skill (competence) should be 50 CAS procedures/year, performed and documented by each operator. This disagrees with the recent conclusion of the Carotid Stenting Trialists' Collabora- tion (CSTC) that CAS should only be performed by operators with an annual procedure volume $\geq 6$ cases/year [75].

A recent review of the literature [76] indicated that, where year-on-year data were available, published stroke and death rates for CAS showed improvements with time. While advances in technology and pharmacology may be responsible in part, these improvements of outcomes in both early and contemporary time-frames, together with the consistency of the results, suggest the presence of a learning curve. In active CAS units, it may take almost two years before the stroke/death rate falls below an arbitrary $5 \%$ threshold. This implies that a log be maintained of each procedure performed and that this log be reviewed periodically by independent experts. These experts may be the same individuals who validate the inci- 
Table 6. Technical requirements for performance of carotid artery stenting

\begin{tabular}{|c|c|c|}
\hline Angiographic skills & \multicolumn{2}{|c|}{$\begin{array}{l}\text { Vascular access skills } \\
\text { Selection of guidewires and angiographic catheters } \\
\text { Appropriate manipulation of guidewires and catheters } \\
\text { Use of 'closed-system' manifold }\end{array}$} \\
\hline Interventional skills & \multicolumn{2}{|c|}{$\begin{array}{l}\text { Guide catheter/sheath placement } \\
\text { Deployment and retrieval of embolic protection devices } \\
\text { Pre- and post-dilation } \\
\text { Stent positioning and deployment }\end{array}$} \\
\hline \multirow[t]{3}{*}{$\begin{array}{l}\text { Recognition and management of } \\
\text { intraprocedural complications }\end{array}$} & Cerebrovascular events & $\begin{array}{l}\text { Stroke or cerebrovascular ischemia } \\
\text { Embolization } \\
\text { Hemorrhage } \\
\text { Thrombosis, dissection } \\
\text { Seizure and loss of consciousness }\end{array}$ \\
\hline & Cardiovascular events & $\begin{array}{l}\text { Arrhythmias } \\
\text { Hypotension } \\
\text { Hypertension } \\
\text { Myocardial ischemia/infarction }\end{array}$ \\
\hline & Vascular access events & $\begin{array}{l}\text { Bleeding } \\
\text { Ischemia } \\
\text { Thrombosis }\end{array}$ \\
\hline Management of vascular access & \multicolumn{2}{|c|}{$\begin{array}{l}\text { Proper sheath removal and attainment of hemostasis } \\
\text { Closure device utilization }\end{array}$} \\
\hline
\end{tabular}

dence of events by site, as mentioned in the section of this document on acceptable limits for periprocedural and postsurgical complications.

Although virtual reality may be considered an essential component in accelerating the learning process and may help considerably in avoiding procedural errors during and after actual training, the ICCS/ISO-SPREAD panel considers that, for the time being, no virtual-reality training may replace training in the interventional theatre, because of the implicated responsibility and extreme variability of individual cases. Therefore, actual interventional-theatre training is recommended, under the guidance and supervision of an expert, credentialed interventionist who shall be responsible for presenting the candidate for certification with a log of performed interventions, efficacy information, and neurologist-confirmed, short-term outcomes.

The specific training on individual devices should be the manufacturer's responsibility. For this reason, devicerelated, hands-on sessions, as well as preceptorships and/ or proctorships, must be managed by manufacturers. The specific training package must have been previously approved by the same bodies that have the authority to certify the training program. Interventionists failing to participate in the training for specific devices should not use those devices for their interventions.

\section{Management of CAS Patients}

\section{Recommendation 12: Grade D [C]}

In the absence of contraindications, dual antiplatelet therapy is indicated before and for the two months following carotid artery stenting. Thereafter, antiplatelet monotherapy is indicated. The use of statins and antihypertensive drugs may also be used before and after the procedure if necessary.

\section{Background}

Regardless of the degree of CS, patient management should include a modification of lifestyle focusing on stopping smoking, daily exercising ( $30 \mathrm{~min} /$ day), attaining a normal body mass index $(\leq 25)$, and the following of a Mediterranean diet [77]. Pharmacological treatment can be implemented for blood-pressure control and lipid lowering to achieve an LDL-cholesterol level of $2.5 \mathrm{mmol} / \mathrm{l}$ $(100 \mathrm{mg} / \mathrm{dl})$, or $1.8 \mathrm{mmol} / \mathrm{l}(70 \mathrm{mg} / \mathrm{dl})$ if feasible. In diabetic patients, glucose control should be targeted to obtain a 7\% glycated hemoglobin level.

The Antithrombotic Trialists' Collaboration metaanalysis [78] combined data from 42 randomized studies of 9,706 patients: the incidence of vascular death, nonfatal myocardial infarction, and non-fatal stroke at fol- 
low-up was significantly decreased $(-23 \%)$ using antiplatelet drugs. Low-dose aspirin (75-150 mg daily) was at least as effective as higher daily doses [78].

The efficacy of clopidogrel compared with aspirin was studied in the randomized Clopidogrel Versus Aspirin in Patients at Risk for Ischaemic Events (CAPRIE) trial [79]: at 1.9-year follow-up, the annual combined incidence of vascular death, non-fatal myocardial infarction, and nonfatal stroke was $3.7 \%$ with clopidogrel and $4.9 \%$ with aspirin, with a significant $23.8 \%$ decrease in the clopidogrel group with respect to the aspirin group. This benefit was greater than in patients enrolled for coronary artery disease or stroke studies. The benefit from dual antiplatelet therapy was found to be small and did not justify its recommendation, due to the increased risk of bleeding $[80,81]$. Even if the use of antiplatelet agents has not been specifically addressed in CS patients, on the basis of these trials we suggest that low-dose aspirin (or clopidogrel in the case of aspirin intolerance) is administered to all patients with supra-aortic vessel disease, irrespective of symptoms [82].

However, the optimal anticoagulation regimen remains undetermined in patients undergoing CAS. Patients are generally pretreated with dual antiplatelet therapy for at least $4-5$ days prior to admission. After CAS, dual antiplatelet therapy (aspirin and clopidogrel or ticlopidine) is generally recommended only in the early postoperative period (4-8 weeks). A small, randomized trial comparing aspirin alone with double antiplatelet therapy for CAS was terminated prematurely due to high rates of stent thrombosis and neurological events in the aspirin-alone group [83].

Regardless of initial cholesterol concentration, the effectiveness of statins in patients with symptomatic cerebrovascular disease is well proven. The Stroke Prevention by Aggressive Reduction in Cholesterol Levels (SPARCL) study [84] evaluated the results of high-dose atorvastatin $(80 \mathrm{mg} /$ day) versus placebo in 4,731 patients with transient ischemic attacks or stroke: patients allocated to atorvastatin had a significant $26 \%$ relative risk reduction in the primary endpoint of fatal or non-fatal stroke at five years. The benefit from statin therapy was even more pronounced in the 1,007 CS patients enrolled in the trial, with a $33 \%$ reduction in stroke, a $43 \%$ reduction in major coronary events, and a $56 \%$ reduction in carotid revascularization procedures at five years [85].

\section{Durability of CAS}

Long-term patency following CAS can be limited by restenosis due to neointimal hyperplasia or recurrent atherosclerosis. The major concern for the durability of CAS has been that the plaque - which is completely removed in CEA - is only remodeled and remains contained behind the strut of the stent, so that the only protection against restenosis and or late embolization is the scaffolding of the plaque by means of the stent. The most recent meta-analysis of all randomized clinical trials comparing CEA and CAS found that restenosis was more common during the follow-up after CAS (OR 2.41) [17]. Nevertheless, CAS remains a durable procedure for stroke prevention, as demonstrated recently by an analysis of long-term results from the ICSS, the largest trial comparing CEA and CAS to date [86]; Moreover, the clinical impact of instent restenosis and the need for reintervention are low and unrelated to the characteristics of the device implanted [87].

As for post-CEA restenosis, the most common strategies with acceptable outcomes for post-CAS restenosis are percutaneous transluminal angioplasty and re-stenting, but surgical options have been reported to have similar results [88-91]. At the moment, the data available does not point to any recommendation for the best treatment to prevent restenosis after CAS, but cilostazol does improve long-term patency after carotid revascularization because of to its inhibitory effect on smooth muscle cell growth $[92,93]$.

\section{Future Tasks}

As with any guideline or consensus statement, this document is valid as long as the evidence on which it is based remains up to date. In such a fast-evolving field of medicine as carotid stenosis management, this time can be quite short. The recommendations of this consensus document are scheduled to be reviewed. The procedures anticipated for interim review consist of an update of the literature. The need to review new topics will be formalized. Updates will entail inclusion/elimination of recommendations as needed, updating of grading if new evidence has emerged, and insertion of new topics anticipated at the interim reviews. The procedures for such updating are anticipated to be the same as those used to develop this document.

\section{Disclosure Statement}

None declared.
Lanza et al. 


\section{References}

1 Cremonesi A, Setacci C, Bignamini A, Bolognese L, Briganti F, Di Sciascio G, Inzitari D, Lanza G, Lupattelli L, Mangiafico S, Pratesi C, Reimers B, Ricci S, de Donato G, Ugolotti U, Zaninelli A, Gensini GF: Carotid artery stenting: first consensus document of the ICCSSPREAD joint committee. Stroke 2006;37: 2400-2409.

-2 Lanza G, Ricci S, Setacci C, Castelli P, Novali C, Pratesi C, Speziale F, Cremonesi A, Morlacchi E, Lanza J, Santalucia P, Zaninelli A, Gensini GF: An update on Italian Stroke Organization guidelines on carotid endarterectomy and stenting. Int J Stroke 2013;Dec 22. Doi: $10.1111 /$ ijs.12226.

3 Scottish Intercollegiate Guideline Network: Sign 50: a guideline developers' handbook. SIGN Publication, February 2001, last updated October 2002.

4 Oxford Centre for Evidence-based Medicine: Levels of Evidence.

5 Sackett DL: Rules of evidence and clinical recommendations on the use of antithrombotic agents. Chest 1989;95:2S-4S

6 Campbell SM, Braspenning J, Hutchinson A, Marshall MN: Research methods used in developing and applying quality indicators in primary care. BMJ 2003;326:816-819.

7 North American Symptomatic Carotid Endarterectomy Trial Collaborators: Beneficial effect of carotid endarterectomy in symptomatic patients with high-grade carotid stenosis. N Engl J Med 1991;325:445-453.

8 Grant EG, Benson CB, Moneta GL, Alexandrov AV, Baker JD, Bluth EI, Carroll BA, Eliasziw M, Gocke J, Hertzberg BS, Katanick S, Needleman L, Pellerito J, Polak JF, Rholl KS, Wooster DL, Zierler RE: Carotid artery stenosis: gray-scale and doppler US diagnosis - society of radiologists in ultrasound consensus conference. Radiology 2003;229:340-346.

-9 European Carotid Surgery Trialists' Collaborative Group: MRC European carotid surgery trial: interim results for symptomatic patients with severe $(70-99 \%)$ or with mild (029\%) carotid stenosis. European carotid surgery trialists' collaborative group. Lancet 1991;337:1235-1243.

10 Mead GE, Lewis SC, Wardlaw JM, Dennis MS, Warlow CP: Severe ipsilateral carotid stenosis and middle cerebral artery disease in lacunar ischaemic stroke: innocent bystanders? J Neurol 2002;249:266-271.

11 Rothwell PM, Eliasziw M, Gutnikov SA, Fox AJ, Taylor DW, Mayberg MR, Warlow CP, Barnett HJ: Analysis of pooled data from the randomised controlled trials of endarterectomy for symptomatic carotid stenosis. Lancet 2003;361:107-116.

12 Bond R, Rerkasem K, Rothwell PM: Systematic review of the risks of carotid endarterectomy in relation to the clinical indication for and timing of surgery. Stroke 2003;34:2290-2301.

-13 Streifler JY, Eliasziw M, Benavente OR, Harbison JW, Hachinski VC, Barnett HJ, Simard
D: The risk of stroke in patients with first-ever retinal vs hemispheric transient ischemic attacks and high-grade carotid stenosis. North American symptomatic carotid endarterectomy trial. Arch Neurol 1995;52:246249.

14 Rothwell PM, Warlow CP: Prediction of benefit from carotid endarterectomy in individual patients: a risk-modelling study. European carotid surgery trialists' collaborative group. Lancet 1999;353:2105-2110.

15 Hurwitz B: Legal and political considerations of clinical practice guidelines. BMJ 1999;318: 661-664.

16 Dworkin R: Limits: the role of law in bioethical decision making. Bloomington, Ind, Indiana University Press, 1997.

17 Bonati LH, Lyrer P, Ederle J, Featherstone R, Brown MM: Percutaneous transluminal balloon angioplasty and stenting for carotid artery stenosis. Cochrane Database Syst Rev 2012;9:CD000515.

18 Endovascular versus surgical treatment in patients with carotid stenosis in the carotid and vertebral artery transluminal angioplasty study (CAVATAS): a randomised trial. Lancet 2001;357:1729-1737.

19 Naylor AR, Bolia A, Abbott RJ, Pye IF, Smith J, Lennard N, Lloyd AJ, London NJ, Bell PR Randomized study of carotid angioplasty and stenting versus carotid endarterectomy: a stopped trial. J Vasc Surg 1998;28:326-334.

20 Brooks WH, McClure RR, Jones MR, Coleman TL, Breathitt L: Carotid angioplasty and stenting versus carotid endarterectomy for treatment of asymptomatic carotid stenosis: a randomized trial in a community hospital. Neurosurgery 2004;54:318-324; discussion 324-325.

21 Roubin GS, New G, Iyer SS, Vitek JJ, AlMubarak N, Liu MW, Yadav J, Gomez C, Kuntz RE: Immediate and late clinical outcomes of carotid artery stenting in patients with symptomatic and asymptomatic carotid artery stenosis: a 5-year prospective analysis. Circulation 2001;103:532-537.

22 Becquemin JP, Ben El Kadi H, Desgranges P, Kobeiter H: Carotid stenting versus carotid surgery: a prospective cohort study. J Endovasc Ther 2003;10:687-694.

23 Yadav JS, Wholey MH, Kuntz RE, Fayad P, Katzen BT, Mishkel GJ, Bajwa TK, Whitlow P, Strickman NE, Jaff MR, Popma JJ, Snead DB, Cutlip DE, Firth BG, Ouriel K: Protected carotid-artery stenting versus endarterectomy in high-risk patients. N Engl J Med 2004; 351:1493-1501.

24 Cambria RP: Stenting for carotid-artery stenosis. N Engl J Med 2004;351:1565-1567.

25 Brott TG, Hobson RW 2nd, Howard G, Roubin GS, Clark WM, Brooks W, Mackey A, Hill MD, Leimgruber PP, Sheffet AJ, Howard VJ, Moore WS, Voeks JH, Hopkins LN, Cutlip DE, Cohen DJ, Popma JJ, Ferguson RD, Cohen SN, Blackshear JL, Silver FL, Mohr JP, Lal
BK, Meschia JF: Stenting versus endarterectomy for treatment of carotid-artery stenosis. N Engl J Med 2010;363:11-23.

-26 Ederle J, Dobson J, Featherstone RL, Bonati LH, van der Worp HB, de Borst GJ, Lo TH, Gaines P, Dorman PJ, Macdonald S, Lyrer PA, Hendriks JM, McCollum C, Nederkoorn PJ, Brown MM: Carotid artery stenting compared with endarterectomy in patients with symptomatic carotid stenosis (international carotid stenting study): an interim analysis of a randomised controlled trial. Lancet 2010; 375:985-997.

-27 Gensicke H, Zumbrunn T, Jongen LM, Nederkoorn PJ, Macdonald S, Gaines PA, Lyrer PA, Wetzel SG, van der Lugt A, Mali WP, Brown MM, van der Worp HB, Engelter ST, Bonati LH: Characteristics of ischemic brain lesions after stenting or endarterectomy for symptomatic carotid artery stenosis: results from the international carotid stenting study-magnetic resonance imaging substudy. Stroke 2013;44:80-86.

28 Ringleb PA, Allenberg J, Bruckmann H, Eckstein $\mathrm{HH}$, Fraedrich G, Hartmann M, Hennerici M, Jansen O, Klein G, Kunze A, Marx P, Niederkorn K, Schmiedt W, Solymosi L, Stingele R, Zeumer H, Hacke W: 30 day results from the space trial of stent-protected angioplasty versus carotid endarterectomy in symptomatic patients: a randomised non-inferiority trial. Lancet 2006;368:1239-1247.

29 Mas JL, Chatellier G, Beyssen B, Branchereau A, Moulin T, Becquemin JP, Larrue V, Lievre M, Leys D, Bonneville JF, Watelet J, Pruvo JP, Albucher JF, Viguier A, Piquet P, Garnier P, Viader F, Touze E, Giroud M, Hosseini H, Pillet JC, Favrole P, Neau JP, Ducrocq X: Endarterectomy versus stenting in patients with symptomatic severe carotid stenosis. N Engl J Med 2006;355:1660-1671.

30 Setacci C, Cremonesi A: SPACE and EVA-3S trials: the need of standards for carotid stenting. Eur J Vasc Endovasc Surg 2007;33:48-49.

-31 Sidawy AN, Zwolak RM, White RA, Siami FS, Schermerhorn ML, Sicard GA: Risk-adjusted 30-day outcomes of carotid stenting and endarterectomy: results from the SVS vascular registry. J Vasc Surg 2009;49:71-79.

-32 Naylor AR: Riding on the crest of a wave! Eur J Vasc Endovasc Surg 2010;39:523-526.

33 Setacci C, De Rango P: A light in the shadows of carotid artery stenting. Eur J Vasc Endovasc Surg 2010;39:527-528.

-34 Zarins CK, White RA, Diethrich EB, Shackelton RJ, Siami FS: Carotid revascularization using endarterectomy or stenting systems (CaRESS): 4-year outcomes. J Endovasc Ther 2009;16:397-409.

35 Wimmer NJ, Yeh RW, Cutlip DE, Mauri L: Risk prediction for adverse events after carotid artery stenting in higher surgical risk patients. Stroke 2012;43:3218-3224.

36 White CJ: Carotid artery stent placement. JACC Cardiovasc Interv 2010;3:467-474. 
- 37 Hobson RW 2nd, Howard VJ, Roubin GS, Brott TG, Ferguson RD, Popma JJ, Graham DL, Howard G: Carotid artery stenting is associated with increased complications in octogenarians: 30 -day stroke and death rates in the crest lead-in phase. J Vasc Surg 2004;40: 1106-1111.

- 38 White CJ, Iyer SS, Hopkins LN, Katzen BT, Russell ME: Carotid stenting with distal protection in high surgical risk patients: the beach trial 30 day results. Catheter Cardiovasc Interv 2006;67:503-512.

39 Gray WA, Yadav JS, Verta P, Scicli A, Fairman R, Wholey M, Hopkins LN, Atkinson R, Raabe R, Barnwell S, Green R: The capture registry: predictors of outcomes in carotid artery stenting with embolic protection for high surgical risk patients in the early post-approval setting. Catheter Cardiovasc Interv 2007; 70:1025-1033.

-40 Roubin GS, Iyer S, Halkin A, Vitek J, Brennan C: Realizing the potential of carotid artery stenting: proposed paradigms for patient selection and procedural technique. Circulation 2006;113:2021-2030.

-41 Longmore RB, Yeh RW, Kennedy KF, Anderson HV, White CJ, Longmore LS, Rosenfield K, Ho KK, Spertus JA: Clinical referral patterns for carotid artery stenting versus carotid endarterectomy: results from the carotid artery revascularization and endarterectomy registry. Circ Cardiovasc Interv 2011;4:8894.

42 Nallamothu BK, Gurm HS, Ting HH, Goodney PP, Rogers MA, Curtis JP, Dimick JB, Bates ER, Krumholz HM, Birkmeyer JD: Operator experience and carotid stenting outcomes in medicare beneficiaries. JAMA 2011; 306:1338-1343.

43 Meier P, Knapp G, Tamhane U, Chaturvedi S, Gurm HS: Short term and intermediate term comparison of endarterectomy versus stenting for carotid artery stenosis: systematic review and meta-analysis of randomised controlled clinical trials. BMJ 2010;340:c467.

-44 Murad MH, Shahrour A, Shah ND, Montori VM, Ricotta JJ: A systematic review and metaanalysis of randomized trials of carotid endarterectomy vs stenting. J Vasc Surg 2011;53: 792-797.

45 Paraskevas KI, Mikhailidis DP, Veith FJ: Comparison of the five 2011 guidelines for the treatment of carotid stenosis. J Vasc Surg 2012;55:1504-1508.

46 Kihara EN, Andrioli MS, Zukerman E, Peres MF, Porto Junior PP, Monzillo PH, Okamoto IH, Massaro AR, Zirretta JC: Endovascular treatment of carotid artery stenosis: retrospective study of 79 patients treated with stenting and angioplasty with and without cerebral protection devices. Arq Neuropsiquiatr 2004;62:1012-1015.

-47 Zahn R, Mark B, Niedermaier N, Zeymer U, Limbourg P, Ischinger T, Haerten K, Hauptmann KE, Leitner ER, Kasper W, Tebbe U, Senges J: Embolic protection devices for carotid artery stenting: better results than stent- ing without protection? Eur Heart J 2004;25: 1550-1558.

48 Coppi G, Moratto R, Silingardi R, Rubino P, Sarropago G, Salemme L, Cremonesi A, Castriota F, Manetti R, Sacca S, Reimers B: Priamus - proximal flow blockage cerebral protection during carotid stenting: results from a multicenter Italian registry. J Cardiovasc Surg (Torino) 2005;46:219-227.

49 Cremonesi A, Manetti R, Setacci F, Setacci C, Castriota F: Protected carotid stenting: clinical advantages and complications of embolic protection devices in 442 consecutive patients. Stroke 2003;34:1936-1941.

50 Kastrup A, Groschel K, Krapf H, Brehm BR, Dichgans J, Schulz JB: Early outcome of carotid angioplasty and stenting with and without cerebral protection devices: a systematic review of the literature. Stroke 2003;34:813819.

51 Reimers B, Schluter M, Castriota F, Tubler T, Corvaja N, Cernetti C, Manetti R, Picciolo A, Liistro F, Di Mario C, Cremonesi A, Schofer J, Colombo A: Routine use of cerebral protection during carotid artery stenting: results of a multicenter registry of 753 patients. Am J Med 2004;116:217-222.

52 Eckert B, Zeumer H: Editorial comment - carotid artery stenting with or without protection devices? Strong opinions, poor evidence! Stroke 2003;34:1941-1943.

53 Brown MM, Featherstone RL, Coward LJ: Carotid artery stenting with and without cerebral protection. Stroke 2004;35:24342435.

54 Naylor AR, Rothwell PM, Bell PR: Overview of the principal results and secondary analyses from the European and north American randomised trials of endarterectomy for symptomatic carotid stenosis. Eur J Vasc Endovasc Surg 2003;26:115-129.

55 Rothwell PM: Carotid endarterectomy and prevention of stroke in the very elderly. Lancet 2001;357:1142-1143.

56 Rothwell PM, Goldstein LB: Carotid endarterectomy for asymptomatic carotid stenosis: asymptomatic carotid surgery trial. Stroke 2004;35:2425-2427.

57 Rerkasem K, Rothwell PM: Temporal trends in the risks of stroke and death due to endarterectomy for symptomatic carotid stenosis: an updated systematic review. Eur J Vasc Endovasc Surg 2009;37:504-511.

58 Halliday A, Mansfield A, Marro J, Peto C, Peto R, Potter J, Thomas D: Prevention of disabling and fatal strokes by successful carotid endarterectomy in patients without recent neurological symptoms: randomised controlled trial. Lancet 2004;363:1491-1502.

59 Halliday A, Harrison M, Hayter E, Kong X, Mansfield A, Marro J, Pan H, Peto R, Potter J, Rahimi K, Rau A, Robertson S, Streifler J, Thomas D: 10-year stroke prevention after successful carotid endarterectomy for asymptomatic stenosis (ACST-1): a multicentre randomised trial. Lancet 2010;376:10741084.
60 Gray WA, Chaturvedi S, Verta P: Thirty-day outcomes for carotid artery stenting in 6320 patients from 2 prospective, multicenter, high-surgical-risk registries. Circ Cardiovasc Interv 2009;2:159-166.

61 Bunch CT, Kresowik TF: Can randomized trial outcomes for carotid endarterectomy be achieved in community-wide practice? Semin Vasc Surg 2004;17:209-213.

62 Pratesi C, Dorigo W, Innocenti AA, Azas L, Barbanti E, Lombardi R, Pratesi G, Pulli R: Reducing the risk of intraoperative neurological complications during carotid endarterectomy with early distal control of the internal carotid artery. Eur J Vasc Endovasc Surg 2004;28:670-673

63 Teso D, Edwards RE, Antezana JN, Dudrick SJ, Dardik A: Do vascular surgeons improve the outcome of carotid endarterectomy? An analysis of 12,618 elective cases in the state of connecticut. Vascular 2004;12:155-165.

64 Abbott AL: Medical (nonsurgical) intervention alone is now best for prevention of stroke associated with asymptomatic severe carotid stenosis: results of a systematic review and analysis. Stroke 2009;40:e573-e583.

65 Setacci C, Chisci E, Setacci F, Iacoponi F, de Donato G, Rossi A: Siena carotid artery stenting score: a risk modelling study for individual patients. Stroke 2010;41:1259-1265.

- 66 Bates ER, Babb JD, Casey DE Jr, Cates CU, Duckwiler GR, Feldman TE, Gray WA, Ouriel K, Peterson ED, Rosenfield K, Rundback JH, Safian RD, Sloan MA, White CJ: ACCF/ SCAI/SVMB/SIR/ASITN 2007 clinical expert consensus document on carotid stenting: a report of the American college of cardiology foundation task force on clinical expert consensus documents (ACCF/SCAI/SVMB/SIR/ ASITN clinical expert consensus document committee on carotid stenting). J Am Coll Cardiol 2007;49:126-170.

67 Hsu JH, Younan D, Pandalai S, Gillespie BT, Jain RA, Schippert DW, Narins CR, Khanna A, Surowiec SM, Davies MG, Shortell CK, Rhodes JM, Waldman DL, Green RM, Illig KA: Use of computer simulation for determining endovascular skill levels in a carotid stenting model. J Vasc Surg 2004;40:11181125.

68 Dayal R, Faries PL, Lin SC, Bernheim J, Hollenbeck S, DeRubertis B, Trocciola S, Rhee J, McKinsey J, Morrissey NJ, Kent KC: Computer simulation as a component of catheterbased training. J Vasc Surg 2004;40:11121117.

69 Ahmadi R, Willfort A, Lang W, Schillinger M, Alt E, Gschwandtner ME, Haumer M, Maca T, Ehringer H, Minar E: Carotid artery stenting: effect of learning curve and intermediateterm morphological outcome. J Endovasc Ther 2001;8:539-546.

$70 \mathrm{SCAI} / \mathrm{SVMB} / \mathrm{SVS}$ clinical competence statement on carotid stenting: training and credentialing for carotid stenting - multispecialty consensus recommendations. Vasc Med 2005; 10:65-75. 
71 Connors JJ 3rd, Sacks D, Furlan AJ, Selman WR, Russell EJ, Stieg PE, Hadley MN: Training, competency, and credentialing standards for diagnostic cervicocerebral angiography, carotid stenting, and cerebrovascular intervention: a joint statement from the American academy of neurology, American association of neurological surgeons, American society of interventional and therapeutic radiology, American society of neuroradiology, congress of neurological surgeons, AANS/CNS cerebrovascular section, and society of interventional radiology. Radiology 2005;234:26-34.

72 Creager MA, Goldstone J, Hirshfeld JW Jr, Kazmers A, Kent KC, Lorell BH, Olin JW, Rainer Pauly R, Rosenfield K, Roubin GS, Sicard GA, White CJ, Winters WL Jr, Merli G, Rodgers GP, Tracy CM, Weitz HH: ACC/ ACP/SCAI/SVMB/SVS clinical competence statement on vascular medicine and catheter-based peripheral vascular interventions: a report of the American college of cardiology/American heart association/American college of physician task force on clinical competence (ACC/ACP/SCAI/SVMB/SVS writing committee to develop a clinical competence statement on peripheral vascular disease). J Am Coll Cardiol 2004;44:941957.

-73 Hobson RW 2nd, Howard VJ, Roubin GS, Ferguson RD, Brott TG, Howard G, Sheffet AJ, Roberts J, Hopkins LN, Moore WS: Credentialing of surgeons as interventionalists for carotid artery stenting: experience from the lead-in phase of crest. J Vasc Surg 2004;40: 952-957.

74 Gray WA, Rosenfield KA, Jaff MR, Chaturvedi S, Peng L, Verta P: Influence of site and operator characteristics on carotid artery stent outcomes: analysis of the capture 2 (carotid acculink/accunet post approval trial to uncover rare events) clinical study. JACC Cardiovasc Interv 2011;4:235-246.

-75 Calvet D, Mas JL, Algra A, Becquemin JP, Bonati LH, Dobson J, Fraedrich G, Jansen O, Mali WP, Ringleb PA, Chatellier G, Brown MM: Carotid stenting: is there an operator effect? A pooled analysis from the carotid stenting trialists' collaboration. Stroke 2014;45: 527-532.

-76 Smout J, Macdonald S, Weir G, Stansby G: Carotid artery stenting: relationship between experience and complication rate. Int J Stroke 2010;5:477-482.

77 Graham I, Atar D, Borch-Johnsen K, Boysen G, Burell G, Cifkova R, Dallongeville J, De Backer G, Ebrahim S, Gjelsvik B, HerrmannLingen C, Hoes A, Humphries S, Knapton M, Perk J, Priori SG, Pyorala K, Reiner Z, Ruilope
L, Sans-Menendez S, Op Reimer WS, Weissberg P, Wood D, Yarnell J, Zamorano JL, Walma E, Fitzgerald T, Cooney MT, Dudina A, Vahanian A, Camm J, De Caterina R, Dean V, Dickstein K, Funck-Brentano C, Filippatos G, Hellemans I, Kristensen SD, McGregor K, Sechtem U, Silber S, Tendera M, Widimsky P, Altiner A, Bonora E, Durrington PN, Fagard R, Giampaoli S, Hemingway H, Hakansson J, Kjeldsen SE, Larsen ML, Mancia G, Manolis AJ, Orth-Gomer K, Pedersen T, Rayner M, Ryden L, Sammut M, Schneiderman N, Stalenhoef AF, Tokgozoglu L, Wiklund O, Zampelas A: European guidelines on cardiovascular disease prevention in clinical practice: executive summary. Fourth joint task force of the European society of cardiology and other societies on cardiovascular disease prevention in clinical practice (constituted by representatives of nine societies and by invited experts). Eur J Cardiovasc Prev Rehabil 2007;14(suppl 2):E1-E40.

78 Baigent C, Blackwell L, Collins R, Emberson J, Godwin J, Peto R, Buring J, Hennekens C, Kearney P, Meade T, Patrono C, Roncaglioni MC, Zanchetti A: Aspirin in the primary and secondary prevention of vascular disease: collaborative meta-analysis of individual participant data from randomised trials. Lancet 2009;373:1849-1860.

79 A randomised, blinded, trial of clopidogrel versus aspirin in patients at risk of ischaemic events (CAPRIE). CAPRIE steering committee. Lancet 1996;348:1329-1339.

80 Bhatt DL, Fox KA, Hacke W, Berger PB, Black HR, Boden WE, Cacoub P, Cohen EA, Creager MA, Easton JD, Flather MD, Haffner SM, Hamm CW, Hankey GJ, Johnston SC, Mak $\mathrm{KH}$, Mas JL, Montalescot G, Pearson TA, Steg PG, Steinhubl SR, Weber MA, Brennan DM, Fabry-Ribaudo L, Booth J, Topol EJ: Clopidogrel and aspirin versus aspirin alone for the prevention of atherothrombotic events. N Engl J Med 2006;354:1706-1717.

81 Cacoub PP, Bhatt DL, Steg PG, Topol EJ, Creager MA: Patients with peripheral arterial disease in the charisma trial. Eur Heart J 2009;30: 192-201.

82 Tendera M, Aboyans V, Bartelink ML, Baumgartner I, Clement D, Collet JP, Cremonesi A, De Carlo M, Erbel R, Fowkes FG, Heras M, Kownator S, Minar E, Ostergren J, Poldermans D, Riambau V, Roffi M, Rother J, Sievert H, van Sambeek M, Zeller T: ESC guidelines on the diagnosis and treatment of peripheral artery diseases: document covering atherosclerotic disease of extracranial carotid and vertebral, mesenteric, renal, upper and lower extremity arteries: the task force on the diagnosis and treatment of pe- ripheral artery diseases of the European society of cardiology (ESC). Eur Heart J 2011; 32:2851-2906.

83 McKevitt FM, Randall MS, Cleveland TJ, Gaines PA, Tan KT, Venables GS: The benefits of combined anti-platelet treatment in carotid artery stenting. Eur J Vasc Endovasc Surg 2005;29:522-527.

84 Amarenco P, Bogousslavsky J, Callahan A 3rd, Goldstein LB, Hennerici M, Rudolph AE, Sillesen H, Simunovic L, Szarek M, Welch KM, Zivin JA: High-dose atorvastatin after stroke or transient ischemic attack. N Engl J Med 2006;355:549-559.

85 Sillesen $\mathrm{H}$, Amarenco P, Hennerici MG, Callahan A, Goldstein LB, Zivin J, Messig M, Welch KM: Atorvastatin reduces the risk of cardiovascular events in patients with carotid atherosclerosis: a secondary analysis of the stroke prevention by aggressive reduction in cholesterol levels (SPARCL) trial. Stroke 2008;39:3297-3302.

86 Featherstone RL, Doig D, Kennedy F, Dobson J, Brown MM: Equivalent long-term disability after carotid artery stenting and endarterectomy in patients randomized in the international carotid stenting study (ICSS): London, European stroke conference, 2013.

87 de Donato G, Setacci C, Deloose K, Peeters P, Cremonesi A, Bosiers M: Long-term results of carotid artery stenting. J Vasc Surg 2008;48: 1431-1440; discussion 1440-1441.

88 Leger AR, Neale M, Harris JP: Poor durability of carotid angioplasty and stenting for treatment of recurrent artery stenosis after carotid endarterectomy: an institutional experience. J vasc surg 2001;33:1008-1014.

89 Zhou W, Lin PH, Bush RL, Peden EK, Guerrero MA, Kougias P, Lumsden AB: Management of in-sent restenosis after carotid artery stenting in high-risk patients. J Vasc Surg 2006;43:305-312.

90 Reichmann BL, van Laanen JH, de Vries JP, Hendriks JM, Verhagen HJ, Moll FL, de Borst GJ: Carotid endarterectomy for treatment of in-stent restenosis after carotid angioplasty and stenting. J Vasc Surg 2011;54:87-92.

-91 Gonzalez A, Drummond M, McCord S, Garrett HE Jr: Carotid endarterectomy for treatment of in-stent restenosis. J Vasc Surg 2011; 54:1167-1169.

-92 Takigawa T, Matsumaru Y, Hayakawa M, Nemoto S, Matsumura A: Cilostazol reduces restenosis after carotid artery stenting. J Vasc Surg 2010;51:51-56.

93 Setacci C, Castelli P, Chiesa R, Grego F, Simoni GA, Stella A, Galzerano G, Sirignano P, De Donato G, Setacci F: Restenosis: a challenge for vascular surgeon. J Cardiovasc Surg (Torino) 2012;53:735-746. 